\title{
Managing the Value of the Organization Based on Organizational Culture
}

\author{
Joanna Gajda \\ Czestochowa University of Technology, Częstochowa, Poland
}

\begin{abstract}
Managing the value of the organization is taking place based on factors forming it. It is becoming possible thanks to such managing operations of the organization, when in the end an image in accordance with expectations, giving the state back to the value of organizations is being got. Creating the goodwill is based among others on immaterial factors, which although they are becoming impossible to include in balance, are taken hold in time value of the organization. Creation of the value of an organization may be based on the organizational culture. The article presents the essence of value management and organization characterized the factors affecting the formation of organizational culture, ways of dealing with an organization aimed at consolidating and strengthening the organizational culture. Sometimes organizations feel the need to change the culture in order to achieve increased efficiency and ensure the success of the company to implement the necessary changes. Therefore, the rest of this article presents the elements to ensure a smooth implementation and consolidation of cultural change.
\end{abstract}

Keywords: managing the value of the organization, the organizational culture, managing

\section{Introduction}

Organizations operating on a brand new market must be able to respond quickly to changes and to develop new management systems in order to be successful. At present, people use management system that focuses on maximizing organization's value thus allowing to achieve an increase in its market value. Management using value as a key point requires replacement of previously existing organizational strategy and focusing on identification of factors that are the source of its value. Currently, it is believed that the value of organization is generated not only by tangible assets, but also by resources that are neither financial nor physical.

Modern organizations, in search of non-financial areas that will allow them to demonstrate their ability to generate value, more often tend to focus on building and developing organizational culture. The aim of this article is to present the impact of organizational culture on management of the value of an organization to increase efficiency of its functioning.

\section{Definition of Company's Value (Goodwill)}

In general, the term "value" is understood as the worth (in material aspect) of something that people want (Panfil, 2006). In business practice, it is often implied that the strength of organization is based on its value expressed in monetary units. However, not all resources in company's possession can be explicitly calculated.

Joanna Gajda, Ph.D., Czestochowa University of Technology, Częstochowa, Poland.

Correspondence concerning this article should be addressed to Joanna Gajda, Bialska 59/3, 42-200 Częstochowa, Poland. E-mail: joannagajda@vp.pl. 
The reason for this is that hidden assets cannot be recognized in balance sheet and profit and loss account (Stefańczyk, 2009). Taking only financial ratios into account during calculation can be dangerous for the organization, because of a loss of opportunity to use and generate resources, which in turn leads to a failure in maintaining market advantage. In contrast, managing intangible asset is beneficial, because it protects the organization from threats arising from market environment, as well as threats occurring within the organization itself (Michalczuk, 2007). According to Bojar and Paździor (2013), the role of intangible assets is becoming increasingly important. These resources create the potential that improves innovations and consequently leads to an increased competitive advantage of the organization.

An intangible asset is also understood as a derivative of terms "knowledge" and "intellectual capital". According to G. Ross and J. Ross (1997), intellectual capital is "the sum of hidden assets of organization that is not included in financial statements, including both what is in the minds of employees and what remains after they left" (p. 38). In contrast, the model of intellectual capital by Low and Kalafut (2004) introduces the idea of economic activity in non-physical aspect and focuses on certain factors that have a significant influence on activity of the organization, provided that it is invested in and is being managed effectively. These factors include such components as: leadership, strategy, communication, brand, reputation, networks, alliances, technologies, processes, human capital, culture, workplace organization, innovation, intellectual capital, and flexibility (Low \& Kalafut, 2004).

Attempts to find ratios of growth and efficiency in non-economic resources have brought attention to problems of organizational culture, due to its inherent values which are believed to be the source of success in organization's activity.

\section{Defining Organizational Culture and Its Components}

Organizational culture is considered to be the property of human teams that are willing and able to choose desirable behaviors that are further used within organization (Galata, 2007). It is the "personality" of the organization, which differentiates it from others. Its personality consists of assumptions and values, which have been prepared and adopted at the stage of solving problems related to adapting the organization to the environment, acquiring team's experience, and shaping internal integration. The scheme of thinking presently used in organization allows to understand organization's practice philosophy as well as learning valuable and desirable attitudes and behaviors (Olszewska, 2004). Concept of Stoner, Freeman, and Gilbert (2002) can be considered as the basis for analysis of the cultural system. They pointed out the existence of three levels of culture:

- artifacts;

- values and norms of behavior;

- main beliefs and assumptions.

Hatch (2002) defined artifacts as visible, tangible, and audible remnants of behavior rooted in cultural standards, values, and assumptions. Artifacts may take the form of:

- language artifacts (language, myths, and legends);

- behavioral artifacts (ceremonies, rituals, and customs);

- physical artifacts (art, technology, and material objects).

Values are principles, objectives, and standards accepted by society and they determine the hierarchy of importance. Values are used as a standard of moral evaluation and they often evoke emotions (Czermiński, 
2001). Values determine what is important and appreciated in life, while standards explain what behaviors are considered as normal or abnormal. Values are closely related to social norms. These are the existing rules that indicate the members of culture which is expected in various situations (Sikorski, 2007). With implementation of standards of behavior in organization comes the occurrence of cultural gap. According to R. Kilmann a cultural gap is the difference between standards generally accepted in the organization and those which are considered to be useful.

Among the most common gaps that are in direct connection to standards are the followings (Januszek \& Sikora, 2000):

- cooperation with other groups;

- innovation;

- intra group behavior;

- freedom and independence of the individual.

Assumptions and beliefs are components of culture's core of the organization. According to Galata (2007), assumptions are determining factors of perception of reality and way of thinking and living. They defined worldview and strengthened beliefs that allow settlement of important issues from the point of view of the organization.

Culture is a set of assumptions that are considered to be true. The truth is indisputable, which permeates every aspect of life in the culture and determines specificity of all kinds of experiences that are affected by it (Hatch, 2002). Cultural standards were categorized, according to fundamental problems of human existence (Czerska, 2003):

- attitude towards environment: It relates to the perception and understanding of the environment. It has a significant impact on decisions of selecting strategy of the organization;

- understanding of truth: It requires thinking about what elements are the foundation of organization's activity and which of the criteria holds true, if you have to choose tradition, authority, knowledge, and experience;

- the nature of man: It talks about features of human nature on which a picture of a worker operating in a certain organization is built. It answers questions: What is manifested through taking a responsibility, a good or a bad will? Is a man lazy or perfectly capable of displaying creativity? Can a man learn completely new abilities or is he to be judged by his present abilities?

- notions of human activity: This includes ideas about activity at work and taking initiative;

- interpersonal relationships: They relate to prevailing notions of relationships in the organization.

\section{The Shape of Organizational Culture}

Forming organizational culture on fundamental values is done with participation of founders of organization as well as employees.

Zbiegień-Maciag (2005) has identified five stages of formulating organizational culture:

(1) Phase 1-Formulation of cultural assumptions: Primary source of organizational culture lies in people responsible for creating organization (Nogalski \& Szpitter, 2012). The most important role in creating and maintaining a culture belongs to the founder, the owner, and their representatives (managers). They form generally accepted standards of behavior. These rules are functional and help to create benefits for employees and organizations. In this phase, culture is unstable and its success is determined by strong personality of 
leaders. According to the principle of "example comes from the top", by observing the behavior of superiors, employees derive from their behavior patterns as soon as they start working with them, and thus co-create the culture of organization. Depending on the style of management, the culture is shaped to be open or closed. In this phase, people sometimes fight for power and prestige. A team is created and it is looking for its own identity and informal leaders.

(2) Phase 2-Development of culture: Teams are seeking for what unites them rather than divides. It is the period of formation of subcultures, identifying with the organization, and seeking a common ground.

(3) Phase 3-Duration of culture: It is a process of stabilization. Human behaviors are assessed.

(4) Phase 4-Maturity and complete stabilization of culture: Teams focus on strong internal control and maintaining the group. Employees manifest aversion to new ideas. In case of growing resistance to new ideas, a change in culture is required.

(5) Phase 5-Changing the culture: Members of the organization change its "personality". Culture is reconstructed and new traditions and patterns are created.

\section{Functions of Organizational Culture}

The process of developing of organizational culture in relation to implementation of two basic functions is considered:

- adaptation — related to the adaptation of group to environment;

- integration - related to reaching an agreement on topics related to internal activity of organization (Sikorski, 2006).

During adaptation phase, the culture has the following functions (Koźmiński \& Piotrowski, 2005):

- helps to understand the mission and strategy of the organization and identify the primary objective of the organization by its participants;

- enables the integration of participants and provides a consensus on objectives which can be derived from the mission and strategy of the organization;

- allows an agreement on actions taken to achieve objectives of the company and increases involvement of participants;

- provides an agreement as to how one should act and what resources can be used;

- offers participants a uniform way to measure results. Thanks to that, individuals and groups are able to see whether objectives have been met and, if so, to what extent;

- allows improvement and modification of objectives, if such modification is necessary.

Thanks to culture, participants are able to develop strategies and ways to change and improve the organization.

The role of culture in internal integration of members comes down to following functions (Koźmiński \& Piotrowski, 2005, p. 377):

(1) providing a common language and notions. Integration takes place when employees communicate with each other using a common language. Sometimes language barriers are the cause of people being seen as inferior or superior;

(2) defining boundaries of the group, establishment of selection criteria of employees, their inclusion in the group and exclusion from it. Effective functioning of the organization is determined by rational use of organizational culture to establish boundaries of individuals and groups within the organization; 
(3) establishment of principles of power and status criteria. Understanding and perception of culture allows to avoid conflicts and aggressive behavior related to the level of one's authority. Culture dictates the preferred system of values for the organization. It shows ways of achieving, maintaining, and using one's authority. It also provides information to employees about rules of referring to subordinates - how to accept or criticize their ideas and decisions;

(4) fulfilling needs of safety and affiliation;

(5) establishing reward and punishment system.

Basing on this system, individuals and groups assess behaviors, attitudes, and decisions. Culture is a determinant of the common system of support and the knowledge of what is good and what is wrong.

\section{Changing the Organizational Culture}

Sometimes there are situations happening that result in dysfunction of some elements of organizational culture that prevent meeting requirements to maintain or improve organization's competitive edge. Thus, there is a need to rebuild organizational culture to increase effectiveness of organization. Among factors which impact elements of culture are the followings (Koźmiński, Jemielniak, \& Latusek, 2009):

- Competitors' activity which forces radical cultural changes is a result of quality and consumer's satisfaction being a top priority;

- Technological changes are requiring greater flexibility and adjusting the offer to meet the needs of consumers. Consumer satisfaction leads to its recognition as a value;

- Change of legislative, although initially it causes a resistance among members of the organization, in the long run, leads to cultural change and creation of new standards and practice;

- The source of a cultural change may be groups operating in the same sector and using similar methods. For instance, companies in the industrial sector are basing on quality management systems that require the use of culturally sanctioned norms and standards;

- The source of cultural change is internationalization. Organizations have a natural tendency to imitate those who are successful on the market, for example, in industry Japanese solutions such as quality circles or zero inventory policy are quite popular; while traders use American methods such as sales, promotions, and discounter;

- Organizational culture is constantly changing, as a consequence of changes in the social structure in which the organization operates. Good examples of these are Japan and Germany, known for their high work ethic. What can be seen recently is an abandonment of old patterns caused by rejuvenation of the workforce, increased levels of wealth, and consumer lifestyle patterns.

The managers have the biggest impact on the effectiveness of changes in organizational culture. Because of their authority, they can contribute to the creation of norms and values that are useful during the implementation of necessary tasks. Thus it is possible to shape the desired behavior of members of the organization and create situations in which decisions taken by managers will find acceptance among employees (Bylok, 2003).

In the opinion of Crozier (1993), constant volatility of the market environment requires a different perspective on the role of employee. With this in mind, it is necessary to replace the one-dimensional worker with someone who has the ability to fully engage in affairs of the organization, to learn individually and collectively, and to evolve when learning. 
Culture plays an important role in increasing tolerance of uncertainty and it is associated with transformation of existing patterns, and assimilation and acceptance of new ones (Romanowska \& Jarosiński, 2005). Therefore, Crozier (1993) suggested that:

- Instead of standardization, a variety of activities that is reflected in creative approach to solving problems should be introduced;

- Instead of a sense of belonging, the need for a sense of harmony in interactions between representatives of different social groups should be indicated;

- The emancipation of the worker should be increased (through stabilizing his work situation by his knowledge, skills, and experience).

To carry out a change in organizational culture, it is necessary to organize efficient human resources function, involving the integration of its strategic objectives with the strategic objectives of the organization. Therefore, cultural change can be done in two ways (Stefańczyk, 2009):

- through cultural revolution. This is a radical change involving firing a large number of employees and replacing them with new ones, and liquidation of the remains of the old system and introduction of a new one. Due to the fact that consequences of adoption of this model can be difficult to predict, it is preferable to avoid revolutionary changes;

- through cultural evolution. It involves careful changes. The first step of this type of change is to diagnose the current state of organizational culture. The second is to define the desired state based on the organization's strategy. The next step is to compare the current situation with the desired one. Then to draw up a long-term plan of changes, one should take care not to lose what is valuable and change everything that needs to be changed.

Regardless of what strategy is chosen, it has to be done from scratch. Involvement of all employees in the process of changing organizational culture should be maximized. It affects shaping of desirable traits, such as:

- a sense of integration with the company;

- a sense of responsibility for tasks performed;

- strengthening emotional bonds among employees;

- creating a sense of belonging to a group.

\section{Conclusions}

In the modern world, competitive advantage of the organization depends (among others) on intangible resources, including organizational culture, which manifests specific characteristics of each company. Culture makes every organization different in certain aspects. This is possible, even if companies operate in the same business sector and have a similar organizational structure.

Organizational culture has a significant impact on performance of the organization and thus can be considered as a management technique and largely contribute to the increase of the market value of the company. In the organization, where there is a culture of a pro-efficiency, people feel an emotional attachment to their workplace and are willing to engage in implementation of objectives of various areas of its business. This proves existence of a positive work environment in which people seek to make changes in organizational culture, as soon as it starts impeding the process of proper adaptation to requirements of the market. Organizations that understand the impact of culture on their effective functioning perceive it as a major strategic tool used to maximize the value of intangible assets and strengthen their own market position. 


\section{References}

Bojar, E., \& Paździor, A. (2013). Human capital-The key to development in the global economy (Faculty of Management, Department of Economics and Economic Management, Lublin University of Technology, Lublin).

Bylok, F. (2003). The role of organizational culture in overcoming crisis situations in the company. In S. Kasiewicz and L. Pawłowicz (Eds.), Goodwill management in times of crisis. Warsaw: CeDeWu Publishing House.

Crozier, M. (1993). The company tapped: How to learn a post-industrial management. Warsaw: Polish Economic Publishing House.

Czermiński, A. (2001). Organization and management. Gdańsk: University of Gdansk Publisher.

Czerska, M. (2003). Cultural change in the organization. The challenges of the modern manager. Warsaw: Difin Publishing House.

Galata, S. (2007). The basics of managing a modern organization. Warsaw: Difin Publishing House.

Hatch, M. (2002). The theory of organization. Warsaw: Polish Economic Publishing House.

Januszek, H., \& Sikora, J. (2000). Sociology of work. Poznań: University of Economics in Poznan Publisher.

Koźmiński, A., \& Piotrowski, W. (2005). Management. Theory and practice. Warsaw: Polish Economic Publishing House.

Koźmiński, A., Jemielniak, D., \& Latusek, D. (2009). Modern look at the organizational culture. Retrieved from http://www.e-mentor.edu.pl/artykul/index/numer/30/id/648

Low, J., \& Kalafut, P. (2004). Intangible goodwill. Cracow: Economics Publishing House.

Michalczuk, G. (2007). Intangible assets-A key factor affecting the value of the company. In E. Orechwa-Maliszewska and J. Paszkowski (Eds.), Management of the value of a company. Białystok: FiZ Publishing House.

Nogalski, B., \& Szpitter, A. (2012). Organizational culture in a management of multicultural organization. In B. Mikuła (Ed.), History and prospects of management studies. Cracow: Foundation of the University of Economics in Cracow.

Olszewska, B. (2004). The basics of management. An enterprise on the threshold of the 21st century. Wrocław: University of Economics in Wroclaw Publisher.

Panfil, M. (2006). Introduction to business valuation. In M. Panfil and A. Szablewski (Eds.), Business valuation methods. The perspective of the customer and the investor. Warsaw: Poltext.

Romanowska, M., \& Jarosiński, M. (2005). Organizational culture. In M. Romanowska (Ed.), The Basics organization and management. Warsaw: Difin Publishing House.

Ross, G., \& Ross, J. (1997). Measuring your company's intellectual performance. Long Range Planning, 30(3), 413-426.

Sikorski, C. (2006). Organizational culture. Warsaw: C.H. Beck Publishing House.

Sikorski, C. (2007). The road to success. Professionalism versus populist organizational culture. Warsaw: Difin Publishing House.

Stefańczyk, M. (2009). Maximization of goodwill by building and developing organizational culture. In R. Barcik and Z. Zontek (Eds.), Goodwill management. Bielsko-Biała: ATH Publishing House.

Stoner, J., Freeman, R., \& Gilbert, D. (2002). Management. Warsaw: Polish Economic Publishing House.

Zbiegień-Maciąg, L. (2005). Culture in the organization. Warsaw: Polish Economic Publishing House. 